\title{
Brasill na Governança Global do Clima, 2005-2012: A Luta entre Conservadores e Reformistas*
}

Eduardo Viola** e Matías Franchini***

\section{Introdução}

A partir de meados da década passada, o Brasil iniciou um processo de profunda mudança que o levou de um agente conservador na área de governança global de clima para uma posição de conservadorismo moderado. Essa transição se sustentou em três pilares básicos, distintos, porém profundamente interdependentes: a trajetória decrescente das emissões de gases de efeito estufa (GEE), a adoção de

* Artigo recebido em 12 de março de 2013 e aprovado para publicação em 6 de maio de 2013.

** Doutor em Ciência Política pela Universidade de São Paulo, professor titular do Instituto de Relações Internacionais da Universidade de Brasília (UnB), coordenador da Rede de Pesquisa em Mudança Climática e Relações Internacionais da mesma instituição e pesquisador sênior do Conselho Nacional de Desenvolvimento Científico e Tecnológico (CNPq). E-mail: eduviola@gmail.com.

*** Doutorando no Instituto de Relações Internacionais da Universidade de Brasília (UnB) e membro da Rede de Pesquisa em Mudança Climática e Relações Internacionais da mesma instituição. E-mail: matifranchi@yahoo.com.ar.

CONTEXTO INTERNACIONAL Rio de Janeiro, vol. 35, nº 1, janeiro/junho 2013, p. 43-76. 
políticas climáticas domésticas e a mudança do perfil internacional de negociação. No entanto, a partir de 2011, o impulso reformista foi desacelerando e finalmente estagnou nos três pilares, embora em graus diversos de intensidade para cada um deles: a trajetória de emissões não foi tão negativa porque a queda das taxas anuais de desmatamento continuou em 2011 e 2012; na política externa, a desaceleração não foi tão grande porque em primeira medida as mudanças de posicionamento não tinham sido tão drásticas; onde houve uma trajetória realmente negativa foi na agenda climática no âmbito doméstico.

Nosso objetivo neste artigo é abordar as alternativas dessa transformação e avaliar suas perspectivas, esforço que implica responder à pergunta sobre o papel do Brasil na estrutura de governança global de clima.

Essa estrutura é em extremo complexa, envolvendo diversas dimensões - econômica, ambiental, de segurança - e diversos atores - públicos e privados, locais e globais. Não obstante, afirmamos que, nessa arquitetura de governança, existe um tipo de agente com capacidades concentradas que lhe permitem ter certo nível de influência sobre o social outcome climático: as potências climáticas. Em tempos em que o regime formal de clima - Convenção Quadro das Nações Unidas sobre Mudança do Clima (CQNUMC) - se torna cada vez mais estéril para avaliar o rumo da política global na área, preferimos uma abordagem baseada na dinâmica desse tipo específico de ator estatal.

Existem três categorias de potências climáticas, dependendo do seu nível de agência na governança do clima: superpotências (China, Estados Unidos e União Europeia), grandes potências (Brasil, Coreia do Sul, Índia, Japão e Rússia) e potências médias. No primeiro grupo, estão os agentes indispensáveis para que qualquer acordo global sobre clima tenha alguma perspectiva de eficiência. O Brasil pertence à segunda categoria, de atores estatais que não possuem capacidade de 


\section{Brasil na Governança Global do Clima,}

2005-2012: A Luta entre Conservadores...

veto sobre um eventual acordo, mas podem operar como catalisadores ou obstáculos ao processo.

Além das considerações sobre poder, existe um segundo conjunto de elementos que é necessário contemplar para avaliar o rumo da governança global do clima: o nível de compromisso climático dos agentes. Definimos compromisso climático como o grau de assimilação que uma determinada sociedade tem da mudança climática como vetor civilizatório principal. Esse compromisso se expressa não apenas na posição internacional de negociação de um Estado, mas na trajetória das emissões de GEE e na densidade das políticas climáticas domésticas. Seguindo esse critério, definimos três tipos de potência: conservadoras, conservadoras moderadas e reformistas. Como a construção de um regime de clima-em termos amplos - depende em última instância da dinâmica das forças conservadoras e reformistas no âmbito do sistema e considerando que os dois primeiros grupos são maioritários, o sistema encontra-se em um impasse em relação à questão climática. Em outra obra (VIOLA et al., 2013), ${ }^{1}$ sintetizamos esse estado de situação com o nome de sistema internacional de hegemonia conservadora.

Para analisar o trânsito do Brasil de potência conservadora a conservadora moderada em 2009-2010 e a estagnação da transição para o campo reformista a partir de 2011, dividimos o trabalho em quatro partes e uma conclusão. Na primeira parte, tratamos do perfil e da trajetória de emissões do país; na segunda, do rumo da política climática doméstica; na terceira, da evolução da política externa na área; e, na quarta, das perspectivas sobre a descarbonização da economia do país. Iniciamos, no entanto, com alguns dados que sustentam a qualificação do Brasil como grande potência, classificação em que predominam os recursos de poder econômico e climático por sobre o poder político e muito mais sobre o poder militar.

Os parâmetros básicos do Brasil em 2012 são: população de 195 milhões de habitantes com taxa de fecundidade de 1,9 filho por mulher, 
PIB (PPP) $)^{2}$ de US $\$ 2,3$ trilhões e PIB per capita (PPP) de US $\$ 11,8$ mil (Banco Munidal (BM); ${ }^{3}$ THE ECONOMIST, 2011). O país emite aproximadamente 2 bilhões de toneladas de carbono equivalente, que corresponde a $4 \%$ do total global, 11 toneladas per capita e 0,9 tonelada de carbono para cada US\$ 1 mil de PIB, e possui alta vulnerabilidade aos efeitos da mudança climática (BM, WRI-CAIT; ${ }^{4} \mathrm{Ma}-$ plecroft Vulnerability Index, 2011). ${ }^{5}$ Consideramos a democracia brasileira como de qualidade média - em que o fato de ter certo nível de compromisso climático tem um peso importante - apesar de a eficiência de governo ser qualificada como média baixa (Worldwide Governance Indicators) ${ }^{6}$ e a desigualdade no país ser muito alta, com um índice Gini de 0,55 (PNUD, 2011).

\section{Queda do desmatamento, redução drástica das emissões e mudança de perfil}

O primeiro pilar que sustenta a transição brasileira para posições mais reformistas no âmbito do clima é a dinâmica de suas emissões de GEE, que na última década passou por um processo de mudanças profundas em termos de trajetória e distribuição setorial, e esteve composta por três movimentos. Ao contrário do que aconteceu com os outros dois pilares, a trajetória das emissões foi a menos afetada pelos retrocessos a partir de 2011, basicamente porque a trajetória do desmatamento na Amazônia continuou em queda.

Até 2005, predominou um paradigma de crescimento econômico hiperintensivo em carbono, junto com um padrão de produção de GEE muito particular para um país de renda média, na medida em que mais da metade das emissões provinham do desmatamento e que o setor energético - de matriz relativamente limpa - pesava pouco na equação final. Os dados da Segunda Comunicação Nacional do Bra- 
sil à CQNUMC - apresentada em 2010 e contendo dados de 2005 refletem ainda essa situação. Segundo este documento, as emissões de $\mathrm{CO}_{2}$ equivalente da economia brasileira em 2005 foram de quase 2,2 bilhões de toneladas, distribuídas da seguinte forma: desmatamento e mudança de uso da terra $(60,6 \%)$, agropecuária $(18,9 \%)$, energia (15\%), indústria $(3,6 \%)$ e tratamento de resíduos $(1,9 \%)$ (BRASIL, 2010). Naquele ano, as emissões do Brasil correspondiam a aproximadamente $6 \%$ do total mundial.

No entanto, entre os anos 2005 e 2009, o país gerou uma mudança radical no perfil e trajetória de emissões. Esse quinquênio foi caracterizado por um singular processo de contração de emissões, derivado de uma drástica queda do desmatamento na Amazônia, cuja taxa média anual passou de quase $22 \mathrm{mil} \mathrm{km}^{2}$ no período 2000-2005 para aproximadamente $7.500 \mathrm{~km}^{2}$ em 2009; ${ }^{7}$ e no Cerrado, onde a queda foi de $14.200 \mathrm{~km}^{2}$ entre 2002 e 2008 para $7.600 \mathrm{~km}^{2}$ entre 2008 e 2009 . O ápice do processo de contração foi o ano de 2009 , quando convergiram o controle do desmatamento com os efeitos da crise financeira internacional sobre a economia brasileira. Como resultado, a produção de GEE em 2009 foi aproximadamente $20 \%$ menor do que a de 2005 .

O ano de 2010 inaugura a terceira etapa. Em primeiro lugar, as emissões do país voltaram a crescer, estimuladas dessa vez não pelo desmatamento, mas pela forte expansão dos outros setores econômicos - o PIB cresceu 7,5\% nesse ano com um alto consumo de gasolina. Em segundo lugar, e como resultado do anterior, o perfil brasileiro de emissões se tornou mais similar ao de outros países de renda média, com um aumento da participação relativa dos setores modernos da economia - energia, indústria, agropecuária e resíduos - na pauta de produção de GEE vis-à-vis o setor LULUFC (land use, land use change and forestry; uso da terra, mudança do uso da terra e florestas). Assim, em 2012, aproximadamente $25 \%$ das emissões vieram 
do desmatamento na Amazônia, 10\% do Cerrado, 32\% da energia, $25 \%$ da agricultura, $5 \%$ da indústria e $3 \%$ de resíduos.

Podemos, então, afirmar que 2010 inaugura uma nova etapa no perfil climático do país, sendo esse o primeiro ano do Brasil moderno em termos de emissões. Nesse novo perfil, no entanto, velhas características subsistem: significativa porção da matriz energética derivada de hidrelétricas (85\%), grande desenvolvimento da produção de etanol para transporte (15\%) e forte crescimento das emissões da pecuária (VIOLA; FRANCHINI, 2012).

Esse abandono progressivo do desmatamento como fonte emissora principal traz novos desafios para a transição do Brasil para uma economia de baixo carbono, na medida em que já foram esgotadas as opções de mitigação mais baratas e fáceis. Isso se deve ao fato de que a trajetória declinante das emissões brasileiras não teve como causa uma revolução do baixo carbono, apenas o controle de uma atividade ilícita que tem pouco impacto no crescimento econômico. Como consequência, a nova situação obriga o país a adotar políticas de mitigação mais compatíveis com uma economia avançada. A elaboração e a implementação dessa agenda não apenas mais recursos, mas também maior capacidade de articulação e gestão em todos os níveis de governo. Nesse sentido, com a mudança de perfil, desaparece uma das particularidades que o Brasil tinha em relação às demais potências climáticas: o baixo custo da descarbonização.

\section{A transição doméstica: crescimento da consciência social e lei do clima}

O segundo pilar da transição brasileira para uma posição mais reformista está representado por uma série de medidas orientadas a abordar especificamente a questão climática na área da política interna, e o elemento de maior destaque foi a aprovação da lei do clima (Lei n ${ }^{\circ}$ 
Brasil na Governança Global do Clima,

2005-2012: A Luta entre Conservadores...

12.187, de 29 de dezembro de 2009). Esse avanço foi tão relevante quanto imprevisto, e colocou o país em um clube seleto, entre União Europeia, Japão, Coreia do Sul, Suíça e Noruega - potências reformistas que internalizaram a questão climática na sua arquitetura jurídica. ${ }^{8}$

Essa trajetória positiva, não obstante, começou a desacelerar a partir de 2011, e no início de 2013 encontra-se totalmente estagnada, afetada por alguns movimentos negativos de relevância, como a expansão significativa do setor petroleiro, a adoção do novo código florestal, a nova política industrial de promoção incondicional da indústria automobilística, a redução das tarifas de energia elétrica, a redução de impostos para evitar altas no preço da gasolina, o agravamento dos problemas no setor de transportes e fundamentalmente, a falta de avanço dos planos setoriais da Política Nacional sobre Mudança do Clima (PNMC). O governo brasileiro, que tinha se comportado como uma força relativamente reformista em 2009-2010, recou para posições profundamente conservadoras a partir de 2011.

\subsection{Políticas climáticas pré-2009:} a mitigação como subproduto

Existe um histórico de políticas consistentes com a redução de emissões no Brasil antes de 2009, que tiveram resultados expressivos nesse campo, mas cuja criação e implementação não estiveram motivadas pela política da mudança climática. Duas áreas se destacam: desmatamento e etanol.

\section{a) Desmatamento}

O histórico do desmatamento na Amazônia antes de 2005 é desastroso, com medias anuais que oscilaram entre os 10 mil km² (1991) e os quase 30 mil (em 1995 e 2004). A média do período 1988-2004 foi de pouco mais de $18.400 \mathrm{~km}^{2}$. E, apesar de a partir de 1993 se desenvol- 
ver e consolidar a ideia do valor da floresta, os instrumentos de política pública necessários para defender na prática esse valor estiveram ausentes.

No entanto, a partir de 2005 se produz uma mudança radical na tendência que inicia um período em que o vetor-chave é o controle do desmatamento - sendo ele, além disso, mais produtivo e a conversão da floresta, mais seletiva e eficiente. Como resultado, as taxas anuais vão sistematicamente caindo - de quase 28 mil km² em 2004 para aproximadamente $4.650 \mathrm{~km}^{2}$ em 2012.

Cimentada na reforma do código florestal de 1996, na lei de gestão de florestas públicas de 2006 e na criação do serviço florestal, a redução do desmatamento a partir de 2005 é explicada por cinco fatores principais (VIOLA; FRANCHINI, 2012): 1) o aumento da capacidade institucional e da implementação da lei pelo Estado nacional; 2) a criação de extensas áreas protegidas; 3 ) a atuação de grandes organizações não governamentais (ONGs) internacionais e nacionais junto

\section{Figura 1}

Evolução Anual do Desmatamento na Amazônia: 1988-2012 ( $\left.\mathrm{km}^{2}\right)$

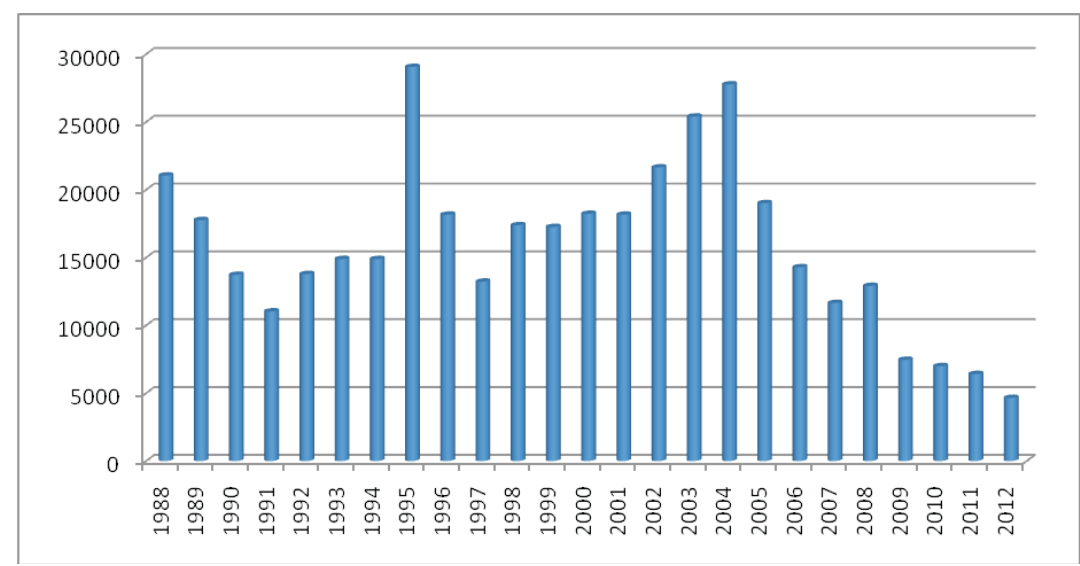

Fonte: Elaboração própria com base em dados do PRODES-IMPE. Disponível em: <http://www.obt.inpe.br/prodes/prodes_1988_2011.htm>. Acesso em: 18 jun. 2012. 
a empresas importadoras e comerciantes dos países desenvolvidos; 4) a gradual cooperação de vários governos estaduais da Amazônia com o governo federal; e 5) alguns períodos de declínio nos preços da soja e da carne; no entanto, houve uma ruptura da correlação histórica entre desmatamento e preços.

A redução do desmatamento quebrou dois mitos no Brasil: da impotência, com relação à capacidade da sociedade brasileira de controlar o desmatamento na Amazônia, e da inevitabilidade do uso imediatista dos recursos naturais, originado na quase total destruição das Matas Atlântica e da Araucária no século XX. Esse movimento teve profundas consequências para a política de clima, como veremos.

\section{b) Etanol}

A outra política pública pré-2009 de grande impacto sobre a trajetória das emissões brasileiras foi o estímulo à produção de etanol, lançada com elevados subsídios na década de 1970 e que se transformou ao longo dos anos em um desenvolvimento economicamente competitivo no combate à mudança climática em nível global. Sem o programa, as emissões de carbono locais seriam em 2012 aproximadamente $15 \%$ maiores. Em 2010, o etanol respondia por cerca de $19 \%$ da matriz energética do país, atrás apenas do setor de petróleo e à frente do de hidreletricidade (BRASIL, 2010).

Por outro lado, desde 2006, o presidente Lula captou quão estratégica é para o Brasil a constituição de uma economia global de biocombustíveis. A diplomacia do etanol teve presença destacada até meados de 2007, e foi avançada do ponto de vista do interesse nacional, mas dissonante com a posição do Brasil de aliado da China, da Índia e da Indonésia nas negociações de mudança climática. No entanto, entrou em decadência após a descoberta do pré-sal. 
Eduardo Viola e Matías Franchini

\subsection{Política climática pós-2009: a transformação}

Até meados de 2009, as políticas públicas de mitigação e adaptação à mudança climática tinham sido muito limitadas, com histórico de poucos recursos alocados. Foi apenas no final de 2008 que um progresso sólido na área começou a tomar forma, quando movimentos de diversos setores sociais e políticos começaram a afetar mais profundamente o comportamento do governo federal. De particular importância foram os movimentos da sociedade civil, de setores empresariais ligados à economia de baixo carbono e do Ministério do Meio Ambiente (MMA), que passou a questionar de forma mais direta a posição do Ministério das Relações Exteriores (MRE) sobre a questão do clima.

O primeiro passo em termos de policy foi dado em dezembro de 2008, quando o Brasil anunciou um novo "Plano Nacional para as Mudanças Climáticas”, que estabelecia metas nacionais obrigatórias, incluindo um cronograma para redução drástica no desmatamento na Amazônia até 2017. Apesar da relevância no momento de seu lançamento, o plano foi superado pela lei climática em 2009, como veremos a seguir.

Em 2009, ano de forte aumento da atenção pública sobre a agenda do clima em parte alimentada pelas expectativas exageradas da Cúpula de Copenhague (COP 15), renovaram-se as pressões sobre o governo brasileiro. Os governos dos estados amazônicos formaram o Fórum da Amazônia e pediram, em julho, mudança da posição brasileira com relação às florestas, mais especificamente à aceitação por parte do Brasil de que o desmatamento evitado fizesse parte do Mecanismo de Desenvolvimento Limpo ou de qualquer outro novo mecanismo de mercado - tipo REDD - ${ }^{9}$ envolvendo créditos de carbono que pudessem emergir das negociações no âmbito da CQNUMC. Esse 
Brasil na Governança Global do Clima,

2005-2012: A Luta entre Conservadores...

questionamento apontava para os fundamentos da posição brasileira desde as negociações do Protocolo de Quioto, como veremos.

Paralelamente, nos meses de junho a setembro, formaram-se três coalizões empresariais demandando mudanças na política climática brasileira. A primeira coalizão, a Aliança de Empresas Brasileiras pelo Clima, demandava basicamente redução do desmatamento na Amazônia e aceitação de mecanismos de mercado para o desmatamento evitado. A segunda coalizão, a Carta Aberta ao Brasil sobre Mudanças Climáticas, propunha um compromisso formal do país nas negociações climáticas e políticas consistentes de redução da curva de crescimento de emissões. Finalmente, a Coalizão de Empresas pelo Clima pedia que o Brasil assumisse compromisso definido de redução de emissões em 2020 com o ano-base de 2007 e não apenas redução da curva de crescimento de emissões.

Outra dinâmica que impactou profundamente o rumo das definições climáticas do governo brasileiro foi o processo de eleições presidenciais. Nesse sentido, até julho de 2009, parecia que a questão climática não teria relevância na campanha, se considerado o perfil e campanha conservadora dos principais candidatos, Dilma Rousseff e José Serra.

No entanto, a consolidação da candidatura presidencial de Marina Silva mudou o conteúdo do debate eleitoral, elevando a importância dos temas da sustentabilidade e da transição para uma economia de baixo carbono e obrigando o presidente Lula e sua candidata a aumentarem a importância da questão climática no debate público nacional. O efeito foi tal que impactou na mudança da posição oficial do Brasil no caminho à COP 15 de dezembro de 2009. Após a significativa votação em favor de Marina Silva no primeiro turno da eleição, os candidatos mais votados se viram na necessidade de fazer uma série de promessas relativas a uma agenda mais sustentável, que não fazia parte de sua plataforma original. 
Os resultados desses movimentos no âmbito da sociedade e da política brasileiras foram rápidos e significativos, tomando corpo definitivo em novembro de 2009, quando o governo federal anunciou um plano de mitigação de emissões relativamente ambicioso. Um mês antes, o ministro do Meio Ambiente Carlos Minc tinha aumentado sua ofensiva para mudar a posição oficial e, depois de intensas negociações, nas quais o MRE e o Ministério da Ciência e Tecnologia (MCT) resistiram, em 13 de novembro foi anunciada a nova posição do governo.

A iniciativa foi posteriormente assumida como compromisso voluntário no âmbito da COP 15 e incorporada à PNMC, estabelecida por Lei Federal (12.187) em dezembro de 2009. O compromisso tem as seguintes características fundamentais: 1) é de tipo voluntário, mas envolve a disposição de assumir compromisso em um tratado internacional; 2) refere-se ao desvio da curva de crescimento das emissões em relação à expectativa de emissões futuras num cenário business as usual (BAU) e não a uma meta obrigatória com relação ao ano base de 1990; e 3) o Brasil compromete-se a reduzir emissões entre $36 \%$ e $39 \%$ com relação à expectativa de emissões projetadas para 2020 no cenário BAU, que seriam de 2,7 bilhões de toneladas de $\mathrm{CO}_{2}$ e. No compromisso voluntário, essas emissões são reduzidas para 1,6 bilhão.

Em relação à lei do clima, depois de significativos esforços do bloco parlamentar ambientalista, o Congresso Federal aprovou o projeto entre outubro e dezembro de 2009, que foi sancionado em janeiro de 2010 com alguns vetos significativos do presidente Lula, particularmente em relação a fontes renováveis de energia e ao abandono progressivo dos combustíveis fósseis.

A normativa, única entre os países que não pertencem à Organização para Cooperação e Desenvolvimento Econômico (OCDE) até fins de 2011 (quando a China aprovou uma lei de mudança climática), esta- 
beleceu a PNMC, cujo objetivo geral é a compatibilização do desenvolvimento com a estabilidade do sistema climático, e envolve a redução das emissões antrópicas de GEE.

Seguindo as diretrizes da lei, o governo iniciou a regulamentação em 2010 com base nos cinco planos setoriais correspondentes aos compromissos apresentados na COP 15 (conforme Tabela 1).

\section{Tabela 1}

Proposta de Redução de Trajetória de Emissões Brasileira

\begin{tabular}{|c|c|c|c|c|c|}
\hline \multirow{2}{*}{$\begin{array}{l}\text { Ações de Mitigação } \\
\text { Uso da terra }\end{array}$} & \multirow{2}{*}{$\begin{array}{c}2020 \\
\text { Tendencial } \\
1.084 \\
\end{array}$} & \multicolumn{2}{|c|}{$\begin{array}{l}\text { Amplitude da } \\
\text { redução } 2020 \\
\text { (mil ton } \mathrm{CO}_{2} \mathrm{e} \text { ) }\end{array}$} & \multicolumn{2}{|c|}{$\begin{array}{l}\text { Proporção de } \\
\text { Redução }\end{array}$} \\
\hline & & 669 & 669 & $24,7 \%$ & $24,7 \%$ \\
\hline $\begin{array}{l}\text { Desmatamento na Amazônia } \\
\text { (redução de } 80 \% \text { ) }\end{array}$ & - & 564 & 564 & $20,9 \%$ & $20,9 \%$ \\
\hline $\begin{array}{l}\text { Desmatamento no Cerrado } \\
\text { (redução de } 40 \%)\end{array}$ & - & 104 & 104 & $3,9 \%$ & $3,9 \%$ \\
\hline Agropecuária & 627 & 133 & 166 & $4,9 \%$ & $6,1 \%$ \\
\hline Recuperação de pastos & - & 83 & 104 & $3,1 \%$ & $3,8 \%$ \\
\hline Integração Lavoura Pecuária (ILP) & - & 18 & 22 & $0,7 \%$ & $0,8 \%$ \\
\hline Plantio direto & - & 16 & 20 & $0,6 \%$ & $0,7 \%$ \\
\hline Fixação biológica de nitrogênio & - & 16 & 20 & $0,6 \%$ & $0,7 \%$ \\
\hline Energia & 901 & 166 & 207 & $6,1 \%$ & $7,7 \%$ \\
\hline Eficiência energética & - & 12 & 15 & $0,4 \%$ & $0,6 \%$ \\
\hline $\begin{array}{l}\text { Incremento do uso de } \\
\text { biocombustíveis }\end{array}$ & - & 48 & 60 & $1,8 \%$ & $2,2 \%$ \\
\hline $\begin{array}{l}\text { Expansão da oferta de energia por } \\
\text { hidrelétricas }\end{array}$ & - & 79 & 99 & $2,9 \%$ & $3,7 \%$ \\
\hline $\begin{array}{c}\text { Fontes alternativas ( } \mathrm{PCH}, \\
\text { bioeletricidade, eólica) }\end{array}$ & - & 26 & 33 & $1,0 \%$ & $1,2 \%$ \\
\hline Outros & 92 & 8 & 10 & $0,3 \%$ & $0,4 \%$ \\
\hline $\begin{array}{l}\text { Siderurgia - substituir carvão de } \\
\text { desmate por plantado }\end{array}$ & - & 8 & 10 & $0,3 \%$ & $0,4 \%$ \\
\hline TOTAL & 2.703 & 975 & 1.052 & $36,1 \%$ & $38,9 \%$ \\
\hline
\end{tabular}

Fonte: Brasil (2009).

Para uma segunda etapa, ficou o processo de regulamentação dos outros planos setoriais: 1) transportes (cargas e passageiros); 2) indús- 
tria de transformação e de bens de consumo duráveis; 3) indústria química fina e de base; 4) indústria de papel e celulose; 5) mineração; 6) indústria da construção civil; e 7) serviços de saúde.

Outra ação importante adotada pelo governo brasileiro em relação ao clima foi a criação do Fundo Nacional sobre Mudança do Clima, com a finalidade de assegurar recursos para projetos de mitigação e adaptação. O fundo é administrado por um comitê gestor vinculado ao Ministério do Meio Ambiente, representantes do Poder Executivo federal e representantes do setor não governamental, sendo o BNDES a instituição financeira responsável.

Simultaneamente à elaboração da legislação sobre clima em nível federal, o estado de São Paulo também sancionou uma lei própria. Nesse caso, o conteúdo é ainda mais avançado do que a lei federal, uma vez que estabelece metas de redução de emissões de $20 \%$ em 2020 , com relação ao ano de referência, 2005. Essa lei é também explicitamente obrigatória, e sua aplicação diz respeito principalmente aos setores de energia, indústria e transportes. Por essa razão, é muito semelhante à legislação equivalente na União Europeia, Japão e Coreia do Sul. Devido ao seu nível de sofisticação, os objetivos estabelecidos pela legislação de São Paulo são mais difíceis de realizar do que os da lei federal.

\subsection{Os retrocessos na agenda: 2011-2012}

A partir de 2011, o rumo da política doméstica brasileira começou a ser cada vez menos convergente com a agenda climática proposta em 2009 e 2010. Não apenas o tópico abandonou o discurso governamental, mas essa indiferença se concretizou numa série de ações e omissões que listamos a seguir. A estagnação da implementação da lei do clima é o principal indicador da posição marginal da questão climática no Brasil após o ápice de 2009-2010. Dos cinco planos ini- 
Brasil na Governança Global do Clima,

2005-2012: A Luta entre Conservadores...

ciais, aqueles que já estão em fase relativamente avançada de implementação e com resultados concretos - Amazônia e Cerrado - já vinham sendo desenvolvidos antes da aprovação da norma. Parte do plano de agricultura também está em andamento - Plano Agricultura de Baixo Carbono (ABC) -, embora os produtores ainda não se inclinem a utilizar os créditos disponíveis. O plano de energia apresenta grandes incertezas, especialmente em relação ao rumo das hidrelétricas na Amazônia, e o plano de siderurgia ainda está em desenvolvimento.

Os outros sete planos estão em uma espécie de limbo, já que são muito difíceis de serem negociados com os setores, têm grandes obstáculos para sua implementação e não têm o suporte de atores políticos e societais relevantes. Existe, no entanto, alguma possibilidade para o plano da indústria de papel e celulose, dependendo do papel da Vale, e da indústria de transformação e bens duráveis, dependendo do papel da Fiesp. Qualquer movimento nesse sentido depende igualmente do grau de cumprimento da lei do clima do estado de São Paulo. Como sugerimos em páginas posteriores, a elaboração e a implementação de um plano efetivo de transportes são quase impossíveis na atual conjuntura.

Outro elemento negativo na evolução da política climática brasileira é a reforma do Código Florestal, já que ela flexibilizou o marco regulatório das florestas e anistiou parcialmente os que desmataram ilegalmente até 2008 , ao mesmo tempo em que deixou manifesto o poder de pressão do setor mais retrógrado do ruralismo, profundamente conservador em termos de compromisso climático. Durante o processo, o governo tentou considerar as posições dos grupos ruralistas e ambientalistas enfrentados; no entanto, acabou operando como força conservadora, ao ser responsável central da última versão da normativa. 
Outros indicadores do rumo negativo da agenda do clima no Brasil são as medidas de estímulo industrial - via redução de imposto sobre produtos industrializados (IPI) - introduzidas em 2012 sem nenhum condicionamento de caráter climático ou ambiental, o "zeramento" da Contribuição de Intervenção no Domínio Econômico (CIDE) sobre importação e produção de petróleo e derivados para evitar novo aumento no preço dos combustíveis, e a redução das tarifas elétricas em fins de 2012. A prioridade do governo Dilma tem sido o crescimento econômico, sem referência alguma ao pilar ambiental. Essa trajetória conservadora é agravada pela evidência dos limites do crescimento brasileiro em 2011 e 2012 e pela constatação de que as medidas de estímulo ao consumo tem pouca eficácia. Como resultado, aparece uma espécie de obsessão pelo crescimento, inclinação que não é privilégio exclusivo do governo, mas também dos formadores de opinião e da maioria da sociedade.

Nesse sentido, é interessante destacar que o quase abandono da agenda climática/ambiental não teve maiores custos políticos para o governo, que manteve altas taxas de imagem positiva. Atribuímos esse resultado a dois fatores principais que estiveram presentes no momento de auge do compromisso climático brasileiro (2009-2010), sendo que o primeiro ficou diluído ate fins de 2012, só retomando importância com o lançamento do novo partido "Rede Sustentabilidade" em fevereiro de 2013, e o segundo foi efêmero. O primeiro elemento foi a presença de uma força política capaz de articular as demandas do eleitorado identificado com a sustentabilidade e a agenda do clima. Esse núcleo aglutinador foi a candidatura presidencial da ex-ministra Marina Silva pelo Partido Verde. O outro elemento foi de caráter externo: o ambiente favorável para medidas pró-clima que a Cúpula de Copenhague criou em nível global. Essa atmosfera estimulou as autoridades políticas brasileiras a tomar posições mais reformistas na Cúpula como instrumento de afirmação do país como relevante player global. 
Brasil na Governança Global do Clima,

2005-2012: A Luta entre Conservadores...

\section{A transição externa: da paranoia florestal ao compromisso voluntário}

Entre 1994 e 2005, o país se comportou como potência conservadora na área da governança de clima, alternando períodos de liderança global intermediadora e liderança setorial. ${ }^{10}$ A partir de 2006, e com a progressiva consolidação do controle do desmatamento, o Brasil foi adotando posturas mais reformistas em relação à governança internacional sobre florestas em um primeiro momento e ampliada para outros temas da agenda climática em etapa posterior. $\mathrm{O}$ evento simbólico dessa transformação é a adoção do compromisso voluntário de redução de trajetória de emissões assumido em Copenhague em 2009.

\subsection{Desmatamento, paranoia florestal e liderança errática (1994-2005)}

$\mathrm{Na}$ área específica de clima, as delegações brasileiras mantiveram tradicionalmente a postura de que toda a responsabilidade pela redução das emissões era dos países desenvolvidos e, portanto, opôs-se deliberadamente aos compromissos de redução da taxa de crescimento futuro das emissões por parte dos países emergentes. Nesse sentido, o Brasil operou historicamente como um dos líderes do G77+China. O princípio que norteava as propostas do país era de que as emissões de carbono deveriam ser calculadas a partir da acumulação de emissão ocorrida desde o final do século XVIII e não apenas a partir do ano-base de 1990.

A atuação do Brasil durante a negociação do Protocolo de Quioto (1996-2001) foi orientada pela definição do interesse nacional segundo cinco dimensões principais (LEIS; VIOLA, 2008): 1) afirmar o direito ao desenvolvimento como um componente fundamental da 
ordem mundial; 2) promover uma visão do desenvolvimento associada com a sustentabilidade ambiental; 3) promover posição de liderança do Brasil no mundo, em correspondência com o crescimento do prestígio internacional do país durante o governo Cardoso; 4) evitar que o uso das florestas seja objeto de regulação internacional para não correr riscos de que outros países possam questionar o uso econômico da Amazônia; e 5) interpretar radicalmente as responsabilidades comuns, porém diferenciadas.

A posição conservadora do país nesses anos era consistente em termos de interesse nacional estreito, considerando as altíssimas emissões do setor LULUCF na época. A delegação brasileira esteve sempre sob o comando do MCT nos aspectos substantivos e do Itamaraty nos aspectos relacionados ao processo negociador.

Com relação aos sumidouros de carbono, foi assumida uma posição defensiva: a floresta amazônica tornou-se mais um ônus por causa do desmatamento do que um trunfo em virtude do serviço global de sequestro de carbono. O que estava implícito nas declarações dos negociadores brasileiros era que o país não conseguiria conter de maneira significativa o desmatamento. Isso levou o Brasil a se posicionar contra a inclusão do conjunto de propostas em torno do ciclo do carbono, e a assumir uma aliança geral com países emergentes com matriz energética dependente de combustíveis fósseis (China, Índia e Indonésia). Dessa forma, a vantagem da limpa matriz energética brasileira ficou sempre subordinada à desvantagem do desmatamento na formação da posição internacional.

Com a retirada da administração Bush (2001-08) das negociações, o Brasil foi liderança na articulação da aliança entre a União Europeia e os países emergentes, o que possibilitou o sucesso da negociação final do Protocolo. Esse período representa o auge da diplomacia brasileira na área, o único ciclo de liderança global do país no regime (março de 2001 a agosto de 2002), tentando guiar o processo de rati- 
Brasil na Governança Global do Clima,

2005-2012: A Luta entre Conservadores...

ficação mundial do Protocolo até a Rio+10, que aconteceria em agosto de 2002. Naquele momento, o Brasil tinha a melhor posição entre os países emergentes para avançar no processo de negociação, porém a paranoia amazônica evitou que essa transição para uma liderança global se consolidasse. Uma visão alternativa e positiva sobre a Amazônia teria levado o Brasil a assumir um set de alianças diferente, o que talvez influenciasse sobremaneira o perfil final do Protocolo.

A partir de 2003, o jogo de forças domésticas para formação da posição brasileira foi se alterando, criando-se as condições para uma modificação da postura internacional: o MMA passou a ter maior interferência no tema, com destaque para o grande poder da ministra Marina Silva, que tinha o objetivo de criar um comportamento responsável, principalmente em relação ao desmatamento da Amazônia.

Paralelamente, o prestígio internacional brasileiro se consolidou com as políticas macroeconômicas e com o aprofundamento das políticas sociais. Os anos de 2003 e 2004, no entanto, são anos relativamente vazios para o tema de clima tanto para o Brasil quanto para a dinâmica global, apesar de o surgimento do REDD como tópico relevante ter acontecido nesse momento.

\subsection{A transição para o reformismo limitado (2006-2012)}

A partir de 2005, pode ser feita uma atualização das premissas do posicionamento brasileiro, que vai redundar em uma modificação da interpretação radical do princípio de responsabilidades comuns, porém diferenciadas. Essa transformação reformista tem uma influência destacadíssima da trajetória do desmatamento.

A afirmação do direito ao desenvolvimento como um componente fundamental da ordem mundial se manteve, assim como a promoção 
da visão do desenvolvimento associada com a sustentabilidade ambiental, com destaque para a PNMC em 2009.

A promoção de posição de liderança do Brasil no mundo, em correspondência com o crescimento do prestígio internacional do país, teve alterações significativas em razão das transformações domésticas e sistêmicas, com a transição do G7 para o G20, e a criação do Fórum das Grandes Economias sobre Energia e Clima (na sigla em inglês, MEF), ambos os foros onde o país tem participação. Mantendo sua tradição, o Brasil faz forte defesa da CQNUMC como foro adequado para a discussão da problemática do clima e é muito relutante quanto à transição dessa arena para o G20, o MEF ou outros âmbitos dentro da ONU, como o Conselho de Segurança e mesmo na Rio+20 (Conferência das Nações Unidas sobre Desenvolvimento Sustentável).

O abandono da obsessão por evitar que o uso das florestas seja objeto de regulação internacional é o princípio de alteração mais significativo no posicionamento brasileiro nesse período. Com o controle do desmatamento, a paranoia florestal diminuiu, e teve como expressão concreta inicial a proposição do país na COP 12 em Nairóbi (2006), orientada para a criação de um fundo com o objetivo de evitar o desmatamento. Dessa forma, o Brasil se mostrava disposto a aceitar uma regulação internacional na matéria, desde que o financiamento para a mitigação florestal não estivesse baseado em um mercado de carbono, operando um realinhamento com a quase totalidade dos países florestais.

Em 2009, o governo confirmou as mudanças esboçadas nos anos prévios ao anunciar um compromisso voluntário de redução de trajetória de emissões - já detalhado em páginas prévias. De fato, em novembro de 2009, parecia que o Brasil ia retomar a posição de líder global intermediador em escala maior à posição entre 2001 e 2002, já que, além do compromisso, o país anunciou uma parceria com a França 
Brasil na Governança Global do Clima,

2005-2012: A Luta entre Conservadores...

para atingir um acordo substancial na Cúpula de Copenhague, criticando as posturas conservadoras dos EUA e da China.

No entanto, semanas antes da Cúpula, o governo brasileiro recou para o campo conservador ao definir - junto ao G77, China, Índia e África do Sul - uma postura comum intransigente para as negociações. Esse movimento prejudicou a posição brasileira enquanto líder global, que significaria uma posição mais independente, e não totalmente alinhada ao G77, que defendesse a redução da curva de crescimento das emissões dos países emergentes e o ano de pico das emissões, de maneira correspondente ao que diz a ciência. Essa postura conservadora foi repetida na COP 16 de Cancun, no ano seguinte.

Em Durban (COP 17, em 2011) e Doha (COP 18, em 2012), o Brasil apresentou posição mais descolada da China e da Índia em relação às metas de redução de emissões, conseguindo trazer a China para uma posição mais próxima da responsabilidade global e manobrando entre os distintos blocos. No entanto, a diplomacia brasileira ainda privilegiou - e privilegia - o formato da CQNUMC e opera conforme uma visão "brickiana sulista" do mundo. O fato de o Brasil ter assumido um compromisso de redução de curva de emissões não implica que tenha abandonado a divisão rígida do mundo entre Anexo 1 e não Anexo 1, já que não aceita que esses tipos de compromissos voluntários para países emergentes se tornem objeto de regulamentação internacional, mas uma expressão de vontade de cada parte.

Isso demonstra que, apesar dos avanços destacados e a atuação do Brasil como líder intermediador nos bastidores, a continuidade de elementos conservadores nacionalistas conspira contra uma assunção plena do papel de liderança global. Papel que envolve, principalmente, o abandono da tradicional tendência da diplomacia brasileira de alinhar-se automaticamente com os países emergentes e pobres. 


\section{Perspectivas do baixo carbono: desafios do perfil moderno}

Nos três segmentos prévios, consideramos a evolução dos pilares básicos que sustentaram a histórica transição brasileira para posturas mais reformistas na arena da governança do clima até 2010 e a estagnação posterior do processo. Abordamos agora as perspectivas dessa transição, insistindo na necessidade de considerar os novos desafios que o controle do desmatamento coloca à agenda de mitigação, que se aproxima de uma estratégia mais clássica de transição para uma economia de baixo carbono, isto é, com ênfase nos setores modernos da economia. Ao mesmo tempo em que é mais complexa em termos técnicos, essa agenda aparece mais complicada também em termos de resistência política.

Para se ter uma visão clara das perspectivas da política de mudança do clima no Brasil, fazemos a seguir uma análise dos obstáculos e das oportunidades relacionadas com a aplicação das opções de mitigação nos setores emissores mais relevantes.

$\mathrm{Na}$ área de controle de desmatamento, as perspectivas de mitigação são particularmente boas. As ações no setor poderiam ir além dos limites atuais, uma vez que existe algum potencial para a conversão eficiente de floresta: reservatórios para a energia hídrica, manejo florestal sustentável seletivo e culturas seletivas anuais em áreas previamente mapeadas com abundância de solo. Além disso, existe potencial significativo para a agrossilvicultura na maioria das áreas degradadas que foram desmatadas nas duas últimas décadas.

No entanto, é necessário destacar que, a partir de 2010, a taxa de queda do desmatamento na Amazônia e no Cerrado já foi bem menor à dos anos anteriores, e que o efeito final da reforma do Código Florestal é ainda incerto, mas provavelmente negativo. 
Brasil na Governança Global do Clima,

2005-2012: A Luta entre Conservadores...

As perspectivas da agricultura também são bastante positivas. O Brasil está tentando disseminar a ideia de agronegócio com baixa intensidade de carbono, em que os ganhos de produtividade não significam emissões mais elevadas. Esse discurso é baseado no potencial agrícola das terras degradadas, uma utilização mais tecnológica da terra já explorada e expansão progressiva do sistema de plantio direto (CERRI, 2010).

$\mathrm{Na}$ área de energia, merece destaque o petróleo, o setor energético com maior expansão nos últimos anos e que aparece cada vez mais como uma ameaça para a perspectiva de o Brasil se tornar uma economia de baixo carbono. As empresas da área, mesmo que tenham um discurso reformista, são, na sua maior parte, conservadoras, incluindo a Petrobras. Esse movimento pró-petróleo tem a descoberta do pré-sal como principal estímulo, a megacapitalização da Petrobras e a expansão da OXG como maior expressão, e conta com o apoio do governo brasileiro.

Esse movimento já colocou certos limites à política externa brasileira em relação à transição para uma economia de baixo carbono, com a moderação da diplomacia do etanol desde o final de 2007. Em relação a possíveis consequências do pré-sal sobre as emissões do país, as perspectivas também não são boas: já está em curso a expansão do refino e da indústria petroquímica, e a probabilidade de adoção de tecnologias de ponta para captura e sequestro de carbono no setor é mínima.

Em relação ao etanol, a futura expansão da produção do combustível está atrelada em parte à mercantilização do bem no mercado internacional, de forma semelhante ao petróleo. Entre 2006 e 2007, a administração Lula da Silva foi muito ativa na promoção da construção desse mercado. No entanto, novas prioridades econômicas e políticas derivadas da descoberta do pré-sal interromperam essa ação. Se o go- 
verno decidir retomar a iniciativa, deverá garantir que a expansão da produção será feita de forma sustentável e sem desmatamento.

Entrando no subsetor de energia elétrica, as usinas termoelétricas tiveram um período de expansão na primeira administração do presidente Lula, fato que derivou numa leve carbonização da matriz energética. A partir de 2008, esse tipo de projeto saiu dos leilões de energia do governo federal, que passou a privilegiar os grandes empreendimentos hidrelétricos e, em menor medida, projetos eólicos. No entanto, em face dos problemas que enfrenta o desenvolvimento hidrelétrico na Amazônia, a tendência é uma volta das termoelétricas aos leilões de energia.

Os projetos hidrelétricos de grande escala voltaram na segunda Presidência de Lula, depois de alguns anos de estancamento. A expansão dessa atividade será concentrada na região Amazônica - que hoje representa menos de $10 \%$ do total produzido - e deve ser feita com alta eficiência na conversão de floresta. A construção já em curso de duas grandes usinas hidrelétricas no Rio Madeira é, pela primeira vez na história da Amazônia, ecologicamente correta.

No entanto, algumas perspectivas desafiadoras aparecem no horizonte, principalmente pela capacidade de resistência dos setores ambientalistas mais radicais, e pelo fato de os novos projetos serem construídos com pequenos reservatórios. Este último elemento os torna altamente vulneráveis às condições de seca - tendência de provável intensificação nos próximos anos -, reduzindo seu potencial. Existe também uma ligação estreita com a questão do desmatamento: um dos questionamentos mais importantes é se a aplicação da lei será estrita suficiente para evitar que trabalhadores da construção permaneçam na área adjacente das usinas, desmatando terras após a construção.

$\mathrm{Na}$ área de energia solar fotovoltaica não há perspectivas para uma implantação futura significativa, mesmo quando existe enorme po- 
Brasil na Governança Global do Clima,

2005-2012: A Luta entre Conservadores...

tencial. Entre as autoridades políticas e o setor de infraestrutura, há um forte lobby inercial em favor da energia hidrelétrica, que bloqueia qualquer avanço. Ademais, fortes subsídios seriam necessários para generalizar esse tipo de energia. No caso da energia eólica, pelo contrário, uma tendência favorável começou a tomar forma desde 2009, e, embora desde uma posição marginal, o setor teve um crescimento significativo nos últimos três anos, com presença destacável nos leilões de energia de 2009 e 2010 com preços competitivos.

Nos últimos anos, o setor nuclear no Brasil tem utilizado sistemática e intensivamente a questão da mudança climática para influenciar a opinião pública e os tomadores de decisão em seu favor. Nesse sentido, as derivações do acidente na usina japonesa de Fukushima em março de 2011 colocaram alguns obstáculos a essa estratégia. No entanto, é possível afirmar que a continuidade das duas centrais em funcionamento não está em perigo, assim como tampouco está em risco o progresso das obras para finalizar Angra III - que deve ficar pronta até 2015. As incertezas envolvem a construção de quatro novas centrais até 2030 previstas no Novo Plano Nacional de Energia de 2007.

Em relação ao setor industrial, a única referência incluída no compromisso voluntário brasileiro é a substituição de carvão de desmatamento por carvão de florestas plantadas na produção de ferro e aço. A siderurgia é realmente a área potencial mais importante para a redução de emissões no setor: eletricidade de origem hidrelétrica, transporte e logística muito favoráveis do minério de ferro e proporções mais favoráveis entre carvão vegetal e carvão mineral (SCHAEFFER et al., 2011). Nos últimos tempos, houve uma mudança no mindset empresarial sobre a questão, que passou a reconhecer as vantagens potenciais.

$\mathrm{Na}$ área de infraestrutura, grande parte do capital fixo que estará vigente no Brasil em 2050 não está ainda construída, e isso significa uma grande oportunidade em termos de mitigação e adaptação à mu- 
dança climática: planejamento urbano que promova o transporte coletivo e evite o desenvolvimento em áreas vulneráveis - encostas ou locais muito próximos das praias; infraestrutura rodoviária e ferroviária resiliente aos extremos climáticos; rede de dutos de etanol; centrais hidrelétricas que levem em conta as mudanças de precipitação geradas pelo aquecimento global; e variedades de produtos agrícolas mais resistentes às pragas. No entanto, esses processos ainda são muito pouco debatidos.

No novo perfil de emissões brasileiro, a área de transportes é crítica por duas razões: sua proporção crescente nas emissões e por ser de longe a mais complicada em termos de controle de produção de GEE. O setor é intensivo em carbono por tonelada de carga e por passageiro transportado (FGV-EPC, 2011). Todas as modalidades apresentam sérios problemas de déficit de capacidade em várias dimensões (CNT, 2011).

O setor está excessivamente concentrado em rodovias, que respondem por aproximadamente $60 \%$ da matriz e cujos principais problemas são o baixo nível de pavimentação $(13,4 \%)$, a deterioração das poucas vias pavimentadas, que reduz a velocidade e a eficiência energética, e a idade avançada da frota em circulação (FGV-EPC, 2011).

Em relação ao transporte particular, que representa $43 \%$ do transporte urbano de passageiros (FGV-EPC, 2011), o governo incentivou sua utilização como parte do pacote de resposta à crise econômica em 2009 e novamente em 2012, sem preocupação com seus efeitos sobre o consumo de combustível, condições de infraestrutura e emissões de $\mathrm{CO}_{2}$. A frota de carros e caminhonetes passou de pouco mais de 33 milhões em abril de 2008 para cerca de 45 milhões em janeiro de 2012 (Denatran), ${ }^{11}$ com taxas de expansão anual média de aproximadamente $10 \%$ até 2011. Como consequência, a economia brasileira enfrenta um quadro de escassez de gasolina e de etanol. 
Brasil na Governança Global do Clima,

2005-2012: A Luta entre Conservadores...

Sobre o transporte coletivo (até 15 vezes menos intensivo em carbono que o particular), a questão da mudança climática agrega-se ao déficit histórico em termos de bem-estar da população e congestionamento de trânsito. O setor possui fortes lobbies em diversas cidades, e nas regiões metropolitanas brasileiras o trânsito e o transporte têm se tornado crescentemente de baixíssima eficiência.

Por enquanto, não existem sinais de abandono das tendências negativas atuais. A política de transporte brasileira está muito atrelada aos interesses setoriais e corporativos estabelecidos (empresas automobilísticas e lideranças políticas clientelistas relacionadas), de maneira que lógicas universais e de longo prazo não penetram esse bunker corporativo. O lobby do setor automotivo também tem sido particularmente obstáculo à transição para um paradigma menos intensivo em carbono e baseado em estradas.

Apesar de não ter um grande impacto na redução das emissões de carbono, o saneamento básico e a destinação ambientalmente adequada de resíduos, incluindo centrais elétricas alimentadas por metano, são áreas com cobenefícios elevados e probabilidade de ocorrência de grandes melhorias, porque apresentam baixa resistência.

\section{Conclusões: 0 Brasil em transição estagnada e incerta para o campo reformista}

O movimento que tornou o Brasil um agente mais comprometido com a governança global do clima entre 2005 e 2012 foi drástico e inesperado, mas também incompleto e incerto, mostrando-se estagnado nos últimos dois anos do período.

Foi drástico porque, até 2005, o país era um vilão climático por causa do desmatamento e porque, até 2009 , não houve uma política climá- 
tica doméstica significativa, nem compromissos internacionais com a mitigação. No entanto, o país reverteu rapidamente esse panorama apoiado no processo de controle do desmatamento, que levou a uma redução de emissões com crescimento econômico único na história20\% em 2009 com respeito aos níveis de 2005.

Nessa dinâmica, o ano de 2009 marcou uma crucial mudança em direção a uma posição mais reformista. Os governadores amazônicos e parte do empresariado demandaram mudanças relevantes na posição brasileira. A entrada de Marina Silva como candidata presidencial colocou rapidamente a problemática da transição para uma economia de baixo carbono na agenda da campanha eleitoral de 2010. Relacionado a essa mudança, o MMA elevou consistentemente seu perfil desde agosto de 2009, forçando uma sensibilização maior por parte do então presidente Lula e sua candidata Dilma.

Essa tendência se viu definitivamente consolidada em dezembro daquele ano, com a sanção de uma normativa específica sobre clima, que internalizou as metas assumidas voluntariamente no âmbito internacional. De fato, o Brasil poderia ter passado ao campo reformista se tivesse mantido a aliança com a França no âmbito internacional e se tivesse avançado na implementação da PNMC.

O movimento para o campo reformista é, no entanto, inconcluso e incerto pela desaceleração e estagnação do processo nos anos 2011 e 2012 e pela consolidação de forças conservadoras no cenário doméstico. Existem muitas dúvidas em referência à implementação integral da lei do clima que hoje favorece os grupos reformistas; porém, e como ficou destacado no processo de reforma do Código Florestal, as forças conservadoras são poderosas e podem colocar sérios obstáculos à descarbonização da economia do país. Em linha similar, também existem fortes dúvidas sobre o cumprimento da lei do clima do estado de São Paulo, e a trajetória desastrosa do setor de transportes inclina para uma previsão pessimista. 
Brasil na Governança Global do Clima,

2005-2012: A Luta entre Conservadores...

Passados dois anos da administração Dilma e três anos da sanção da lei do clima, os avanços no desenho e implementação dos planos setoriais de energia, transportes, indústria e agricultura são nulos para todo efeito prático. Apenas os planos da Amazônia e do Cerrado estão em funcionamento pleno, mas eles já estavam nessa situação antes de serem incorporados à PNMC. Paralelamente, faz tempo que o argumento ambiental/climático abandonou o discurso de desenvolvimento das autoridades nacionais, acompanhado por um significativo ocaso do MMA como vetor de políticas convergentes com a sustentabilidade.

No âmbito do Congresso, é importante destacar o caráter errático do comportamento dos legisladores - especialmente na Câmara dos Deputados - em relação ao tópico. O movimento levou a uma drástica mudança entre fins de 2009 (aprovação da lei do clima) e meados de 2012 (aprovação da reforma do Código Florestal).

Outro eixo central de incertezas são o rumo do pré-sal e a equação energética no país. Conforme o Brasil apresenta um perfil de emissões mais moderno, o setor de energia aumenta sua participação relativa na produção de GEE e se torna o centro de qualquer política séria de mitigação. Nesse sentido, destaca-se o avanço do complexo petroleiro. No discurso do governo e da própria Petrobras, essa expansão não aparece como contraditória com as perspectivas de o Brasil aprofundar a transição para uma economia de baixo carbono. No entanto, existem fortes motivos para duvidar dessa afirmação.

A evidência empírica mostra que a produção e a exportação de petróleo em grande escala tendem a influenciar o comportamento dos Estados, no sentido de atrasar a descarbonização e estimular posições internacionais conservadoras. O Brasil já sofreu com uma prévia desse tipo de processo com a diplomacia do etanol, que foi central na estratégia internacional do presidente Lula em 2006 e 2007, mas que depois do anúncio da descoberta do pré-sal foi quase abandonada. 
Nesse sentido, a posição da diplomacia brasileira é outro dos elementos que seguram o país no campo conservador. Apesar de ter o potencial, o país não foi capaz de se tornar um líder global na arena de governança do clima, sacrificando esse papel no altar de antigas alianças com o mundo em desenvolvimento, uma categoria hoje carente de qualquer significado. A posição de negociação do Brasil na CQNUMC praticamente não mudou entre Copenhague e Doha. As duas últimas administrações, especialmente o MRE e o MCT, continuaram a priorizar a aliança com os países do BASIC (Brasil, África do Sul, Índia e China).

A maior das incertezas, no entanto, radica na definição do dilema civilizatório central de nossa época em sua formatação local: o crescimento da coalizão reformista na arena sociopolítica brasileira. Nesse sentido, a lei do clima votada em 2009 foi - e ainda é - mais avançada e reformista que a sociedade em termos de compromisso climático. Sua existência obedece em parte ao aproveitamento que as autoridades ambientais - na figura do então ministro Carlos Minc - fizeram da janela de "oportunidade climática" que se abriu no segundo semestre de 2009.

À luz dessas evidências, é possível afirmar que parte do progresso feito no período foi mais fictício do que real. Em primeiro lugar, a redução das emissões e a queda da intensidade de carbono do produto brasileiro no período não foram resultado de uma revolução do baixo carbono, mas de uma queda drástica das taxas anuais de desmatamento a partir de 2005. O que o Brasil fez foi controlar uma atividade ilegal, pouco convergente com a dinâmica de uma sociedade democrática de renda média e com pouca participação no PIB.

Em segundo lugar, o pico de sucesso da agenda climática no Brasil esteve alimentado por dois fatores que no final resultaram efêmeros. O primeiro foi um ambiente internacional favorável para medidas de baixo carbono derivado das expectativas geradas pela Cúpula de Co- 


\section{Brasil na Governança Global do Clima,}

2005-2012: A Luta entre Conservadores...

penhague, o segundo foi o surgimento de um polo político que aglutinou as forças reformistas/ambientalistas, expressado basicamente na candidatura presidencial de Marina Silva pelo Partido Verde. Ambos os fatores elevaram os custos políticos de negar uma agenda ambiental e estimularam o governo a tomar as medidas reformistas referidas.

Desaparecidos esses elementos reformistas, a nova administração federal foi capaz de desenvolver a partir de 2011 uma gestão pouco sensível ao pilar ambiental sem pagar elevados custos políticos. Finalmente, nesse processo de sete anos o governo se comportou como uma força oportunista - adaptando seu comportamento à dialética das forças reformistas/conservadoras -, mas essencialmente operou como uma força conservadora, já que careceu de uma agenda de baixo carbono estável, que abandonou quando a correlação de forças se inclinou para o setor conservador.

\section{Notas}

1. O fato de que o sistema internacional seja incapaz de dar resposta aos maiores desafios da governança global - especialmente a crise climática - o torna conservador.

2. Purchasing Power Parity (PPP), paridade do poder de compra.

3. Disponível em: <http://datos.bancomundial.org/>. Acesso em: 12 fev. 2013.

4. Disponível em: <http://cait.wri.org/>. Acesso em: 9 jan. 2013.

5. Disponível em: <http://www.maplecroft.com>. Acesso em: 25 fev. 2013.

6. Disponível em: <http://info.worldbank.org/governance/wgi/index.asp>. Acesso em: 27 nov. 2012.

7. Disponível em:<http://www.obt.inpe.br/prodes/prodes_1988_2011.htm>. Acesso em: 25 jan. 2013. 
8. Internalizar a mudança climática na estrutura jurídica significa definir claramente os gases estufa como poluentes, mesmo que diferenciados dos outros poluentes de impacto local que afetam a saúde humana.

9. Redução de Emissões por Desmatamento e Degradação Florestal (Reducing Emissions from Deforestation and Forest Degradation).

10. Entendemos por liderança global uma liderança cimentada não apenas na defesa do interesse nacional restrito - liderança setorial -, mas na procura de garantir uma administração cooperativa do bem comum atmosfera.

11. Disponível em: <http://www.denatran.gov.br/frota.htm>. Acesso em: 16 mar. 2012.

\section{Referências Bibliográficas}

BRASIL. Ministério da Ciência e Tecnologia. Segunda comunicação nacional à Convenção-Quadro das Nações Unidas sobre mudança do clima. 2010. Disponível em: <http://www.mct.gov.br>. Acesso em: 2 nov. 2010.

BRASIL. MMA, MAPA, MME, MF, MDIC, MCT, MRE, Casa Civil. Cenários para Oferta Brasileira de Mitigação de Emissões. São Paulo, 13 nov. 2009. Disponível em: <http://www.forumclima.pr.gov.br/arquivos/File/CenariosparaOfertaBrasileiradeMitiga.pdf>. Acesso em: 7 mar. 2011.

CERRI, Carlos. Management Practices for Greenhouse Gas Emission Reduction and Carbon Removal in Brazilian Agriculture, Livestock and Forestry. Piracicaba: Centro de Energia Nuclear na Agricultura/Universidade de São Paulo, 2010. Disponível em: <http://www.fbds.org.br/IMG/pdf/ doc-410.pdf>. Acesso em: 2 jun. 2011.

CNT - Confederação Nacional do Transporte. Plano CNT de transporte e logística. [s.1.]: Confederação Nacional do Transporte, 2011. Disponível em: $<$ http://www.cnt.org.br/Paginas/Plano-CNT-de-Log\%C3\%ADstica.aspx>. Acesso em: 23 set. 2011.

FGV/EPC - Fundação Getúlio Vargas/Plataforma Empresas pelo Clima. Propostas empresariais de políticas públicas para uma economia de baixo carbono no Brasil. 2011. Disponível em: <http://intranet.gvces.com.br/cms/arquivos/recomendacoes_epc.pdf>. Acesso em: 22 jun. 2011. 


\title{
Brasil na Governança Global do Clima,
}

2005-2012: A Luta entre Conservadores...

LEIS, Héctor; VIOLA, Eduardo. América del Sur en el mundo de las democracias de mercado. Rosario: Homo Sapiens/CADAL, 2008.

PNUD - Programa das Nações Unidas para o Desenvolvimento. Relatório do Desenvolvimento Humano. 2011. Disponível em: <http://hdr.undp.org/en/ media/HDR_2011_PT_Complete.pdf>. Acesso em: 25 jan. 2012.

SCHAEFFER, Roberto; FROSSARD, André; LUCENA, Pereira de; SZKLO, Alexandre Salem; BORBA, Bruno Soares Moreira Cesar; NOGUEIRA, Larissa Pinheiro Pupo; RATHMANN; Régis; SORIA, Rafael. Redução de emissões: opções e perspectivas para as áreas de energia, indústria e transporte no Brasil. Rio de Janeiro: Fundação Brasileira para o Desenvolvimento Sustentável, 2011. Disponível em: <http://www.fbds.org.br/IMG/pdf/doc-409.pdf>. Acesso em: 21 jul. 2011.

THE ECONOMIST. Pocket World in Figures. Londres: Profile Books Ltd, 2011.

VIOLA, Eduardo; FRANCHINI, Matías. Climate Policy in Brazil. Public Awareness, Social Transformations and Emission Reduction. In: BAILEY, I.; COMPSTON, H. (Org.). The Politics of Climate Policy in Rapidly Industrialising Countries. Hampshire: Palgrave, 2012.

; LEMOS RIBEIRO, Thais. Sistema internacional de hegemonia conservadora: governança global e democracia na era da crise climática. São Paulo: Annablume, 2013.

\section{Resumo}

\section{Brasil na Governança Global do Clima, 2005-2012: A Luta entre Conservadores e Reformistas}

\begin{abstract}
A área de governança global do clima é definida por dois vetores básicos: poder e compromisso climático. O primeiro faz referência ao impacto de certos atores com capacidades suficientes para influenciar o social outcome climático. O segundo considera como a lógica da governança na área é definida pela dialética entre forças que assimilam o problema climático como crise civilizatória - reformistas - e forças que resistem às transformações necessárias para estabilizar o sistema climático - conservadoras.
\end{abstract}


Neste artigo, usamos essas duas categorias para responder a pergunta sobre o papel do Brasil na estrutura de governança global de clima, e afirmamos que, a partir de meados da década passada, o país atravessou um processo de mudanças que o levou da condição de uma grande potência conservadora para uma posição de conservadorismo moderado. Essa transição se sustentou em três pilares básicos, diferentes: a trajetória decrescente das emissões de gases de efeito estufa (GEE), a adoção de políticas climáticas domésticas e a mudança do perfil internacional de negociação. No entanto, a partir de 2011, o impulso reformista foi desacelerando e finalmente estagnou. O objetivo deste artigo é abordar essa transformação - drástica e inesperada - e avaliar suas perspectivas - na medida em que é inconclusa é incerta.

Palavras-chave: Mudanças Climáticas - Governança Global - Política Externa Brasileira

\section{Abstract}

\section{Brazil in the Global Governance of Climate Change 2005-2012: The Struggle between Reformists and Conservatives}

Two main drivers shape the global governance of climate change: "climate power" and climate commitment. Climate power refers to the level of influence of certain agents over the climate social outcome at the systemic level. Climate commitment recalls the fact that the logic of global climate governance is also defined by the interaction of reformist and conservative forces, with the former willing to take post-sovereigntist measures to tackle the crisis, and the latter resisting any major changes in the way business is conducted.

This article analyses the role of Brazil in global climate governance, considering both climate power and climate commitment. It argues that the country transitioned from a conservative great climate power to a moderate conservative position over the last decade, based on three pillars: reduction of greenhouse gas emissions, the adoption of domestic climate policies, and a shift in its international standing on the issue. However, since 2011 the process has stalled and partially reversed. The aim of this article is to address that transformation and explore its perspectives.

Keywords: Climate Change - Global Governance - Brazilian Foreign Policy 